\title{
VLSI-SoC: An Enduring Tradition
}

\author{
Ricardo Reis $^{1(\bowtie)}$ and Manfred Glesner ${ }^{2}$ \\ ${ }^{1}$ PGMicro/PPGC, Instituto de Informática, \\ Universidade Federal do Rio Grande do Sul, Porto Alegre, Brazil \\ reis@inf.ufrgs.br \\ ${ }^{2}$ Institut für Datentechnik, Mikroelektronische Systeme, \\ Technische Universität Darmstadt, Darmstadt, Germany \\ glesner@mes.tu-darmstadt.de
}

\begin{abstract}
VLSI-SoC series of conferences started in 1981 and this chapter presents a little bit of its history. Since the beginning, the conference moves around the world, showing recent works in the field of VLSI and Systems-onChip design and design automation. The contents of books related to the set of event editions is in some way a witness of the extraordinary evolution of the field in these almost 4 decades.
\end{abstract}

Keywords: VLSI $\cdot$ SoC $\cdot$ EDA $\cdot$ Test $\cdot$ Microelectronics

\section{The Beginning}

The year that Lynn Conway and Carver Mead received the "1981 Electronics Award for Creating a Common Design Culture for the LSI ERA" was the year that started the VLSI-SoC (IFIP TC10/WG10.5 International Conference on Very Large Scale Integration) series of conferences (started as VLSI). The first edition was organized in Edinburgh, UK, from August 18 to 21. The General Chair was Sidney Michaelson and the Program Chair was John Gray, both from the University of Edinburgh. Prof. Sidney Michaelson was also the founder of a new Working Group on VLSI for the International Federation for Information Processing, the WG10.5 (http://www.edinburgh.bcs. org/michaelson.htm). The WG10.5 has developed into one of IFIP's most active groups, regularly organizing workshops and conferences. In 1986, Prof. Sidney Michaelson was presented with the IFIP Silver Core award in recognition of his contribution to the work of that organization. At the time of his death he was an active member of the organizing committee for the tenth anniversary conference, VLSI 91, to be held in Edinburgh later that year. Figure 1 shows the cover of the first proceedings, that was published as a book by Academic Press and edited by John Gray. The book includes 35 papers. The first paper of the book has the title "VLSI and Technological Innovations" and the author was Prof. Carver Mead (CALTECH, USA).

The second edition was organized in Trondheim, Norway, August 16-19, 1983, and O. Landsverk from TU Trondheim was the General Chair. The Program Chair was Prof. François Anceau from TIM3/INPG, France. The proceedings were also published as a book, by North-Holland Publishers (Fig. 2). 


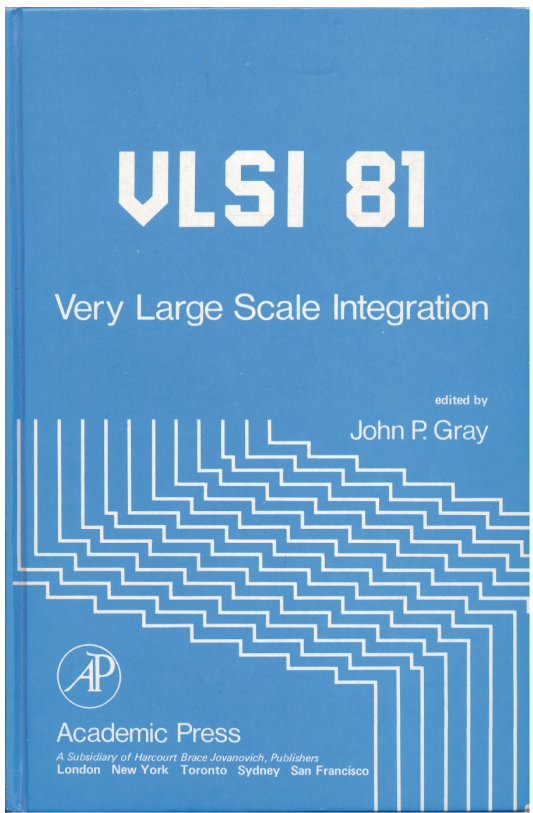

Fig. 1. Cover of the first VLSI conference proceedings published as a book by Academic Press [1].

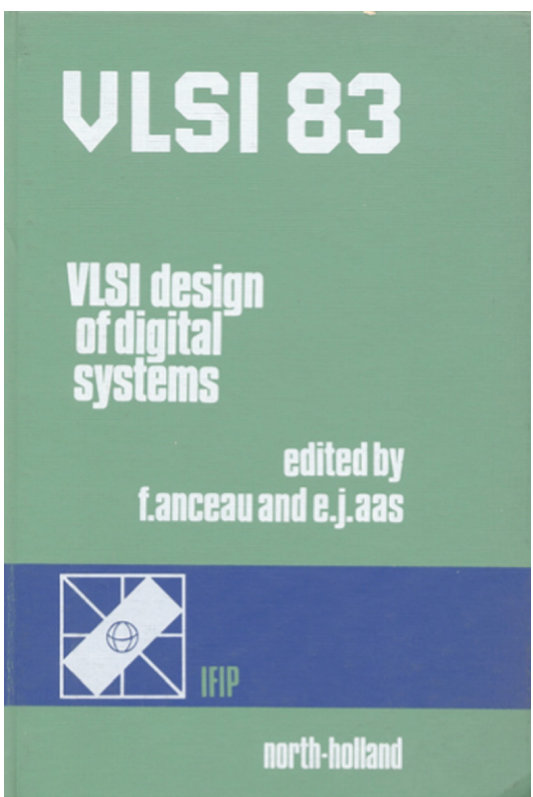

Fig. 2. Cover of the second VLSI conference proceedings published as a book by North Holland [2]. 
The third edition was organized in Tokyo, Japan, August 26-28, 1985. The General Chair was Prof. T. Moto-Oka from University of Tokyo and the Program Chair was E. Hörbst, from the Central Research Division of Siemens Company in Munich, Germany. The proceedings were again published as a book by North-Holland (Fig. 3).

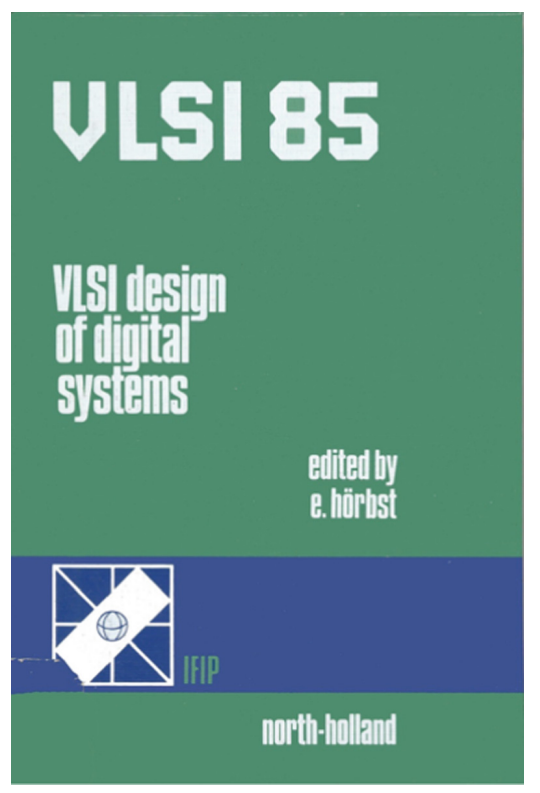

Fig. 3. Cover of the VLSI 1985 proceedings published as a book by North Holland [3].

The fourth edition was organized in Vancouver, Canada, August 10-12, 1987. The General Chair was D.R. Colton from CMC, Canada and the Program Chair was Prof. C.H. Sequin from University of California, USA. The proceedings were again published as a book by North-Holland (Fig, 4).

The fifth edition was organized in Munich, Germany, August 16-18, 1989. The General Chair was Prof. R. Piloty from Technical University of Darmstadt, Germany and the Program Chair was Prof. Gerald Musgrave from Brunel University, UK. The proceedings with 516 pages were again published by North-Holland (Fig. 4). 

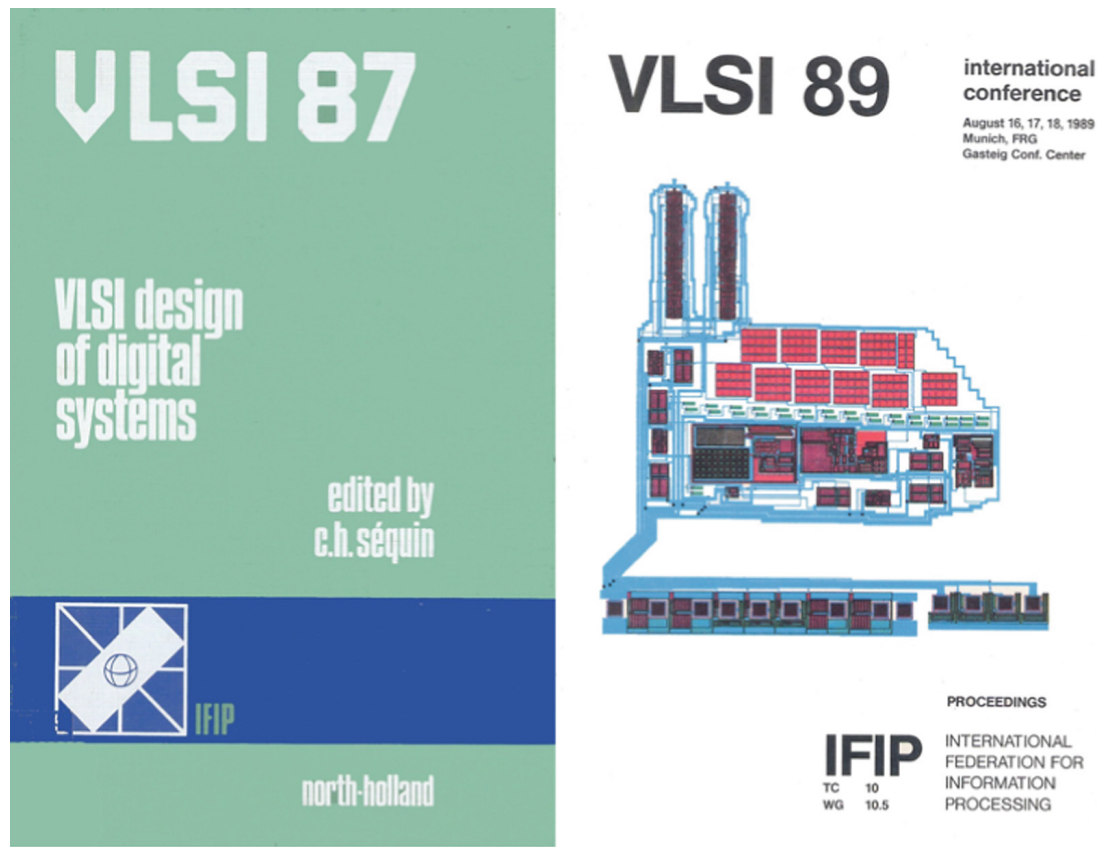

Fig. 4. Covers of VLSI 1987 and VLSI 1989 proceedings published by North Holland [4, 5].

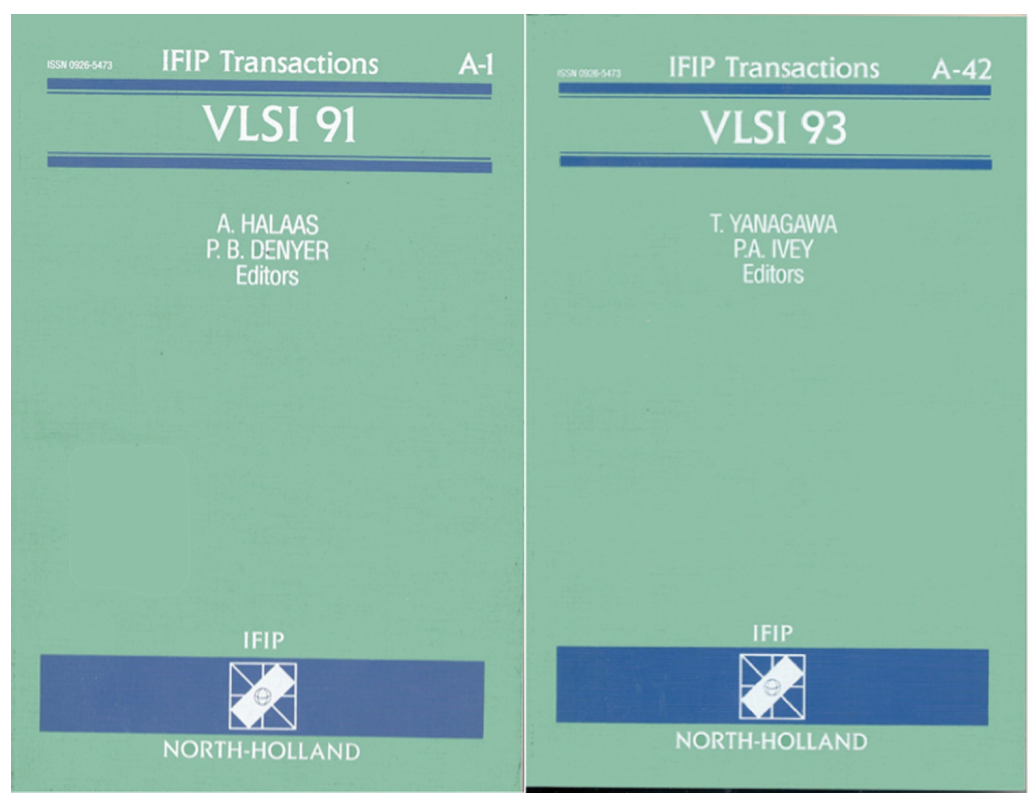

Fig. 5. Covers of the VLSI 1991 and VLSI 1993 proceedings published as a book by North Holland [6, 7]. 


\section{Years 90's}

The 1991 edition was organized again in Edinburgh, Scotland, August 20-22. The General Chair was I. Barron from InMOS, Uk and the Program Chair was Prof. P.B. Denyer from University of Edinburgh, UK. The proceedings were again published as a book by North-Holland (Fig. 5).

The 1993 edition was organized in Grenoble, France, September 6-9, 1993. The General Chair was J. Monnier from ST Microelectronics, France and the Program Chair was Takayuki Yanagawa from NEC, Japan. The proceedings were published by North-Holland (Fig 5).

In 1995, the conference was again in Tokyo, Japan, August 29 to September 1 . The General Chair was Prof. Tatsuo Ohtsuki from Waseda University, Japan and the Program Chair was Prof. Wolfgang Rosenstiel, from University of Tübingen, Germany. This edition was organized together with CHDL 95 (the 12th International Conference on Computer Hardware Description Languages and their Applications) and the first edition of ASP-DAC. The proceedings were published as a joint proceedings of the 3 conferences and published by IEEE (Fig. 6).

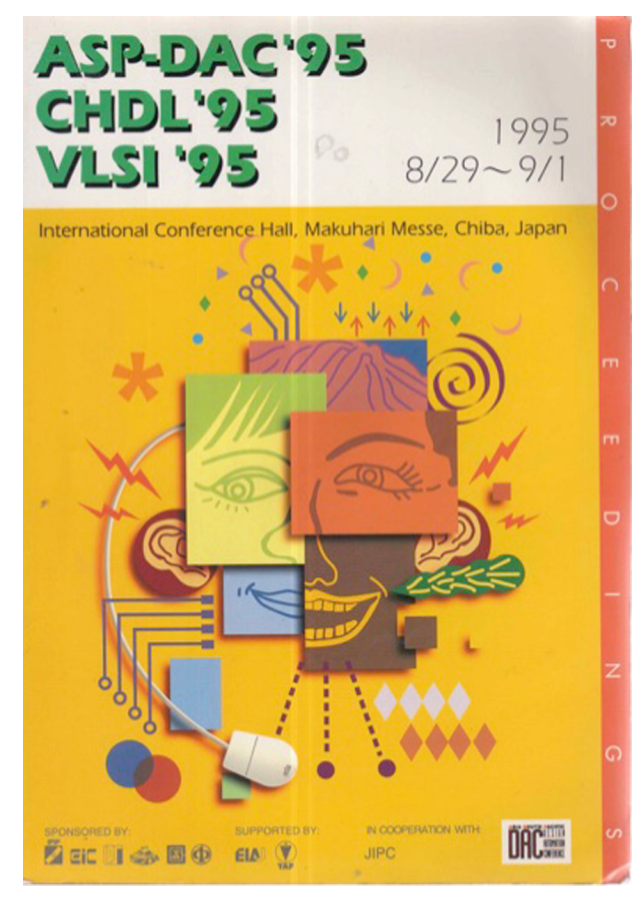

Fig. 6. Cover of the VLSI 1995 proceedings published by IEEE [8].

In 1997, the conference was organized for the first time in South America. The location was Gramado, a small tourist town close to Porto Alegre, South Brazil. It was organized from August 26 to 29. The General Chair was Prof. Ricardo Reis from 
Universidade Federal do Rio Grande do Sul (UFRGS), Porto Alegre, Brazil and the Program Chair was Luc Claesen from IMEC, Belgium. The proceedings with 588 pages was published as a book by Chapman\&Hall Publishers (now Springer) (Fig. 7).

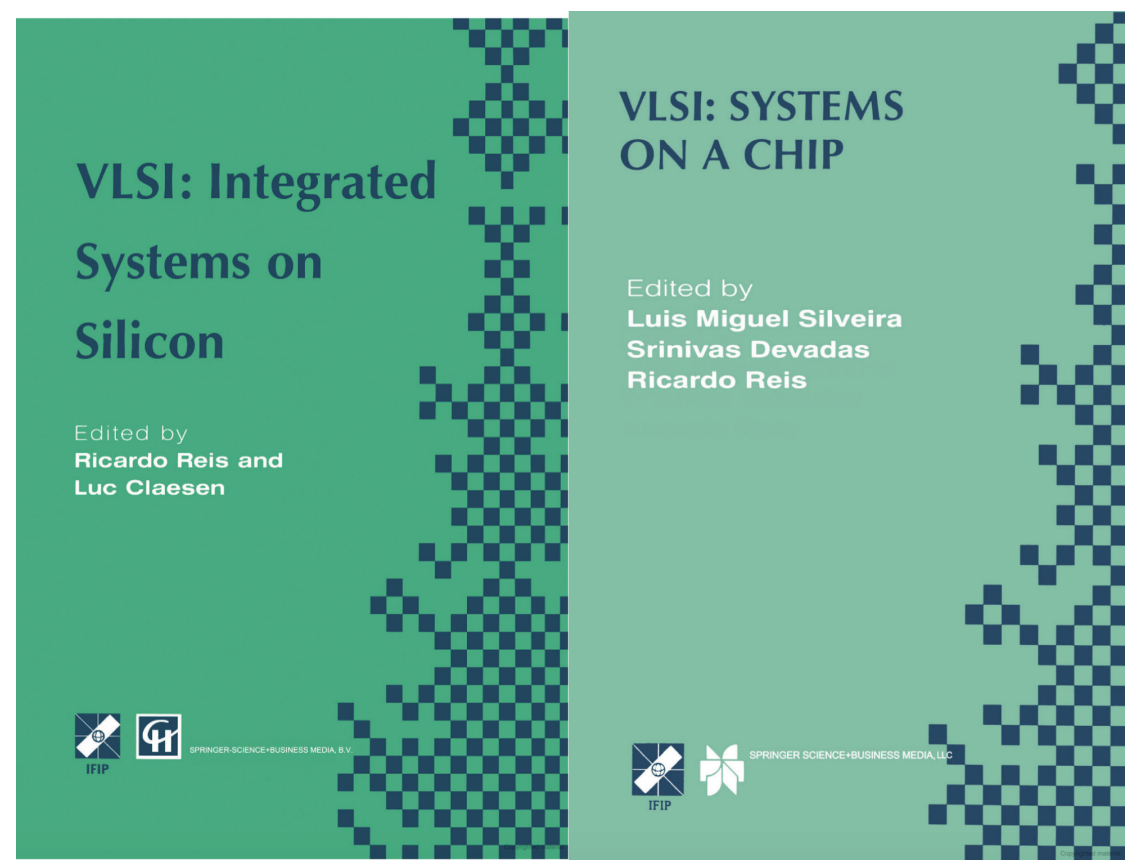

Fig. 7. Cover of the VLSI 1997 book published by Chapman \& Hall and cover of VLSI1999 published by Kluwer Publishers [9, 10].

In 1999, the conference was organized in Lisbon, Portugal. The General Chair was Prof. Luis Miguel Silveira and General Vice-Chair was Prof. José Monteiro both from INESC, Lisbon, Portugal and the Program Chair was Prof. Srinivas Devadas from MIT, USA. There were two Program Co-Chairs, Prof. Peter Ivey from University of Sheffield, UK and Prof. João Marques-Silva from INESC, Portugal. The proceedings were published as a book by Kluwer Publishers (now Springer Nature) (Fig. 7).

\section{Years 2000's}

In 2001, the conference was organized in Montpellier, France. The General Chair was Prof. Michel Robert, from LIRMM, France and the Program Chairs were Christian Piguet from CSEM, Switzerland and Bruno Rouzeyre, from LIRMM, France. The proceedings were published as a post-conference book by Kluwer Publishers (now Springer Nature). During the conference it was distributed to participant a Digest of Papers (Fig. 8). 


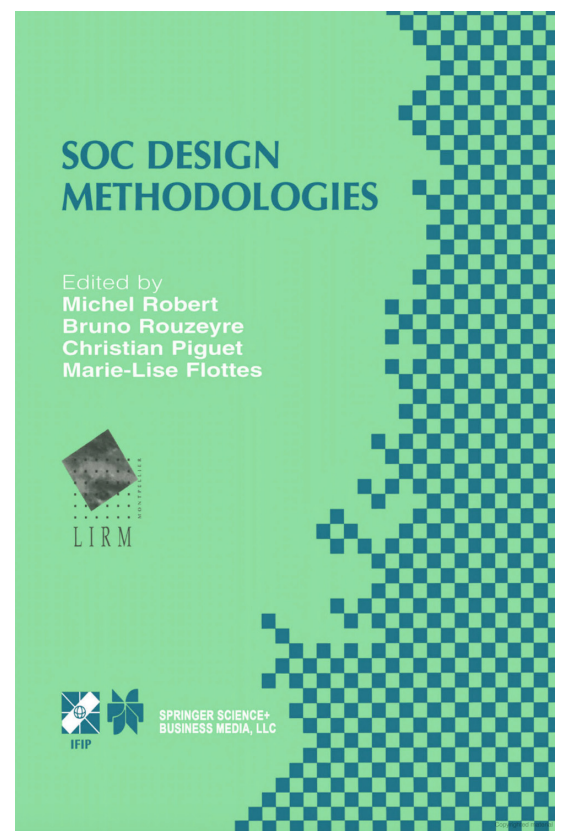

Fig. 8. Cover of the VLSI2001 published by Kluwer Publishers [11]

In 2003, the conference was organized in Darmstadt, Germany. The General Chair was Prof. Manfred Glesner, from TU Darmstadt, Germany and the Program Chairs were Hans Eveking from TU Darmstadt, Germany and Prof. Vincent Mooney, Georgia Tech, USA. During the conference, the proceedings were distributed to participants. Then considering also the presentations done during the conference, for the first time a book was assembled with extended versions of conference best papers (with Springer Publishers) (Fig. 9). Leandro Indrusiak (at that time preparing a double $\mathrm{PhD}$ between TU Darmstadt, Germany and UFRGS, Brazil) has designed a logo for the VLSI-SoC series, that is being used till today (Fig. 10). It was also proposed by Leandro Indrusiak, a new conference call for papers template, that is being used in most of editions since there (Figs. 11 and 12).

In 2005, the conference was organized in Perth, Australia, October 17-19, 2005. The General Chair was Prof. Adam Osseiran from ECU, Australia. The General ViceChair was Stefan Lachowicz, also from ECU. The Program Chairs were Prof. Steve Kang from UC Santa Cruz and Prof. Hans-Joerg Pfleiderer, from University Ulm, Germany. The book with best papers extended versions was again published by Springer (Fig. 13).

From 2005, the conference that was organized each two years, become being organized each year. Prof. Ricardo Reis made the proposal to organize the VLSI-SoC Conference annually. This decision was mainly due to the fact the VLSI-SoC developed as a global conference moving around the world. Being organized each two years as it was, there was a too long time to return to a same region of the world. 


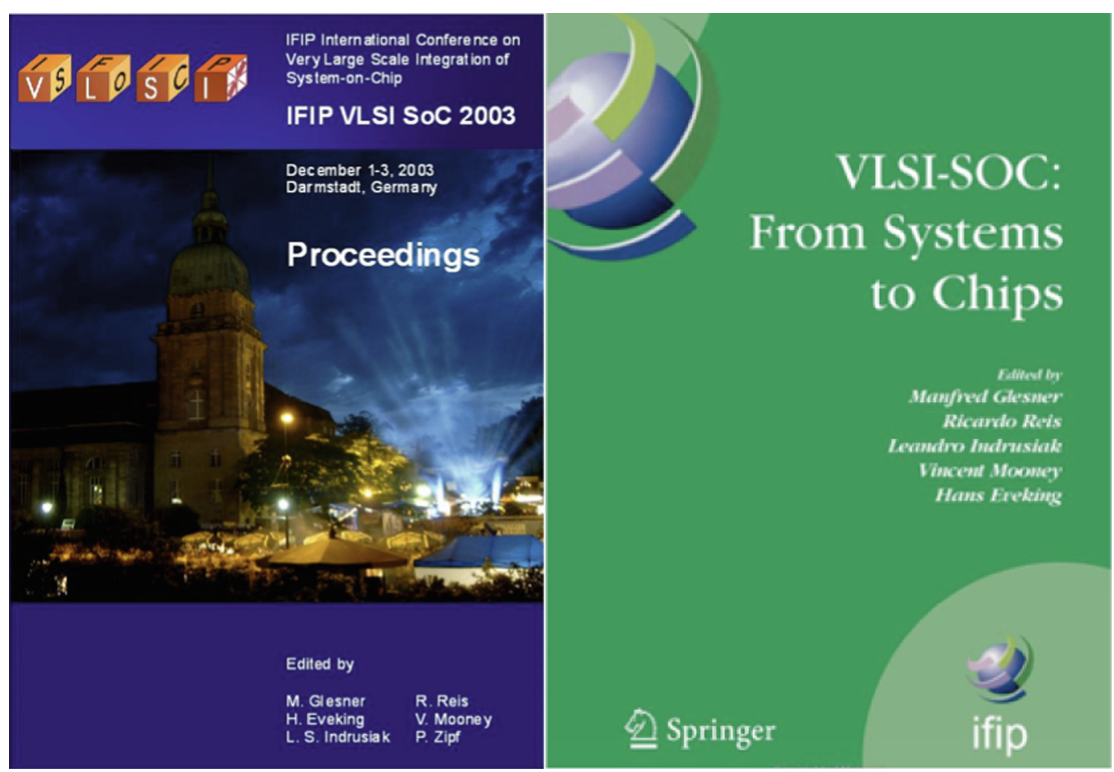

Fig. 9. Cover of the VLSI2003 proceedings and cover of the book with extended versions of best papers published by Springer Publishers [12].

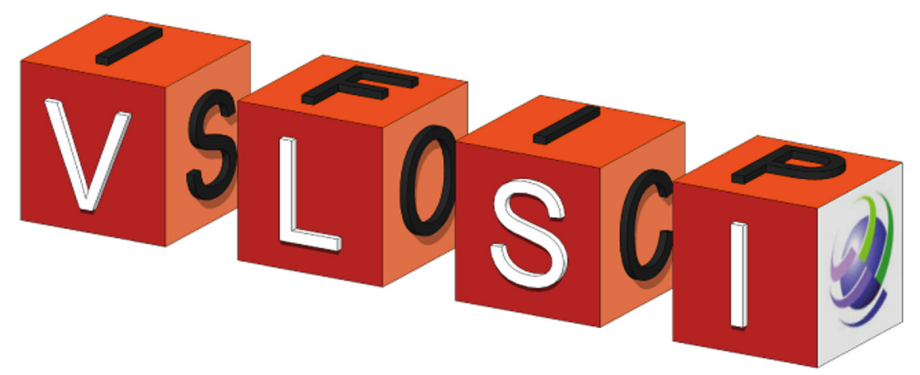

Fig. 10. Logo of the VLSI-SoC series developed by Leandro Indrusiak.

In 2006, the conference was organized in Nice, France, October 16-18, 2006. The General Chair was Salvador Mir from TIMA, Grenoble, France. The Program Chair was Prof. Giovanni De Micheli, from EPFL, Switzerland. The book with best papers extended versions was again published by Springer (Fig. 14).

In 2007, the conference was organized in Atlanta, USA, October 15-17, 2007. The General Chair was Prof. Vincent Mooney from Georgia Tech, USA. The Program Chairs were Prof. Yung-Hsiang Lu, from Purdue University, USA and Prof. Paul Hasler, from Georgia Tech, USA. The book with best papers extended versions was again published by Springer (Fig. 14).

In 2008, the conference was organized in Rhodes, Greece, October 13-15, 2008. The General Chair was Prof. Dimitrios Soudris from University of Thrace, Greece. The Program Chairs were Christian Piguet, from CSEM, Switzerland and Prof. Thanos 

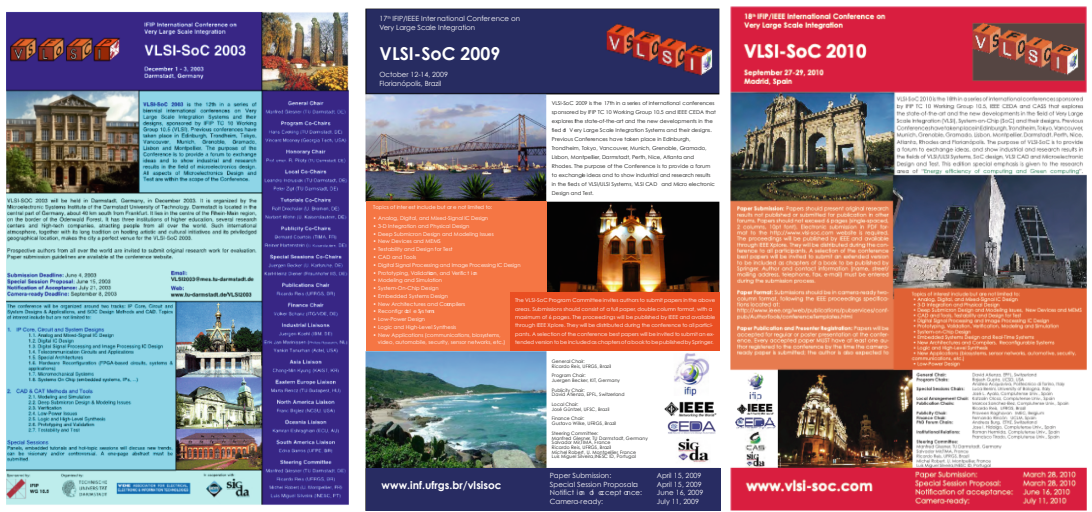

Fig. 11. VLSI-SoC 2003 CFP, that defined a new CFP template and VLSI-SoC 2009 and VLSISoC 2010 CFPs using a template based on the 2003 one.
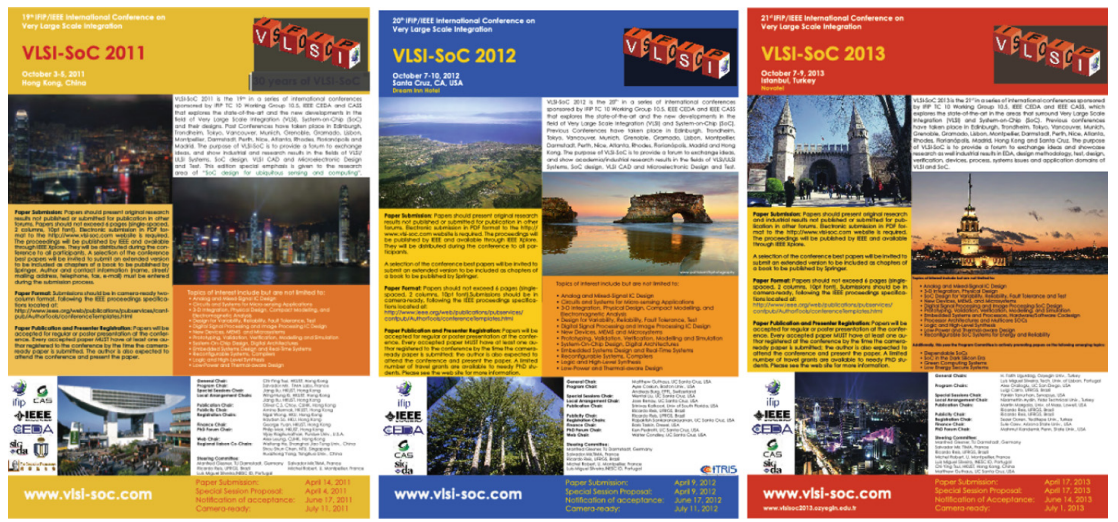

Fig. 12. Some other CFPs using the CFP template: and VLSI-SoC 2011, VLSI-SoC 2012 and VLSI-SoC 2013.

Stouraitis, from University of Patras, USA. The book with best papers extended versions was again published by Springer (Fig. 15).

In 2009, the conference was organized in Florianópolis, Brazil, October 12-14, 2009. The General Chair was Prof. Ricardo Reis from Universidade do Rio Grande do Sul (UFRGS), Brazil. The Program Chair was Prof. Juergen Becker, from KIT, Germany. The Local Organizing Chair was Prof. José Güntzel from Universidade Federal de Santa Catarina, Brazil. The book with best papers extended versions was again published by Springer (Fig. 15). It was the first time that it was organized a PhD Forum as part of the conference. 


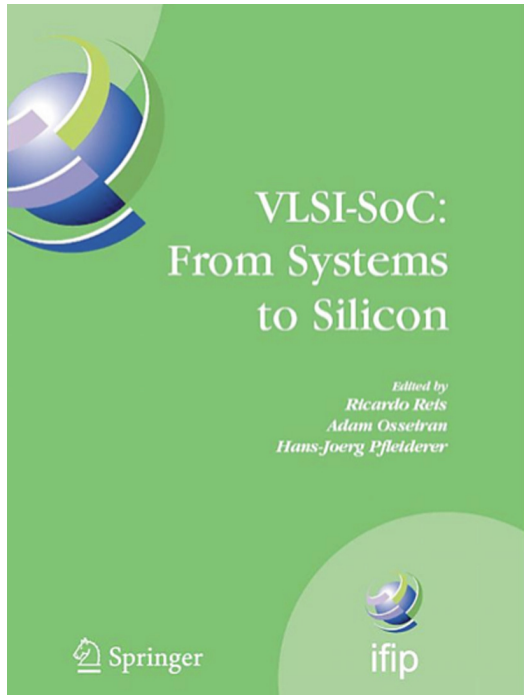

Fig. 13. Cover of the VLSI2005 book with extended versions of best papers published by Springer Publishers [13].
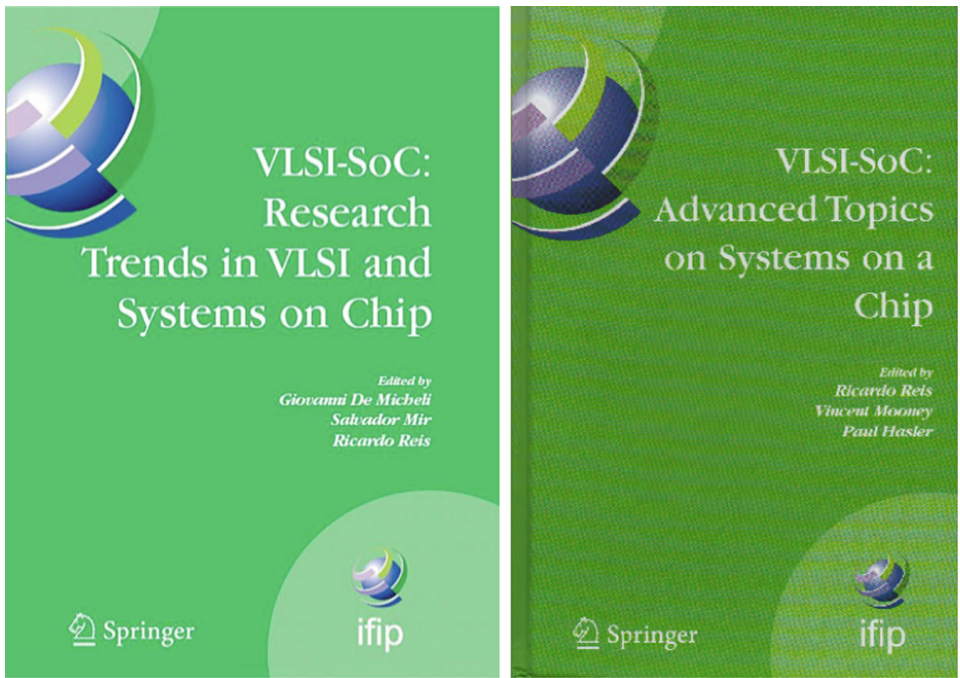

Fig. 14. Covers of the VLSI2006 and VLSI2007 books with extended versions of best papers published by Springer Publishers [14, 15]. 


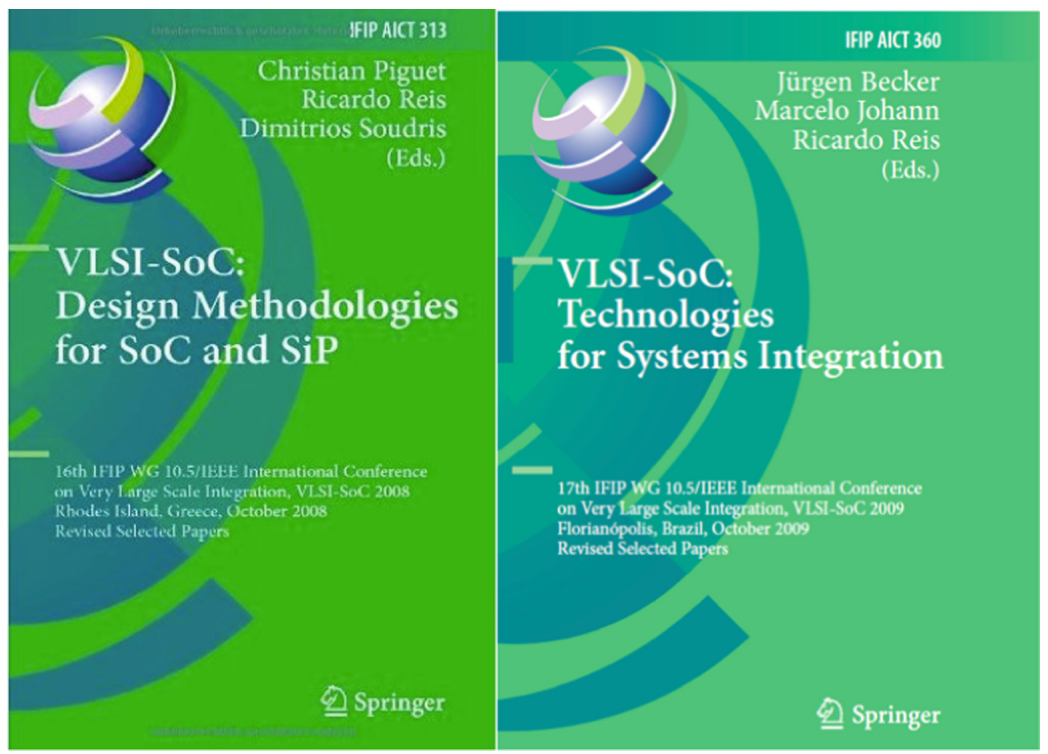

Fig. 15. Covers of the VLSI2008 and VLSI2009 books with extended versions of best papers published by Springer Publishers [16, 17].

\section{Years 2010's}

In 2010, the conference was organized in Madrid, Spain, September 27-29, 2010. The General Chair was David Atienza from EPFL, Switzerland. The Program Chairs were Prof. Rajesh Gupta, from UC San Diego, USA and Prof. Andrea Acquaviva, from Politecnico de Torino, Italy. The book with best papers extended versions was again published by Springer (Fig. 16). In 2011, the event was organized in Hong Kong, October 3-5, 2011. The General Chair was Prof. Chi-Ying Tsui and Program Chair was Salvador Mir from TIMA, INPG, Grenoble.

In 2012, the conference was organized in Santa Cruz, CA, USA, October 7-10, 2012. The General Chair was Prof. Matthew Guthaus from UCSC, USA. The Program Chairs were Prof. Andreas Burg, from EPFL, Switzerland and Prof. Ayse Coskun, from Boston University, USA. The book with best papers extended versions was again published by Springer (Fig. 17). In 2013, the event was organized in Istanbul, Turkey, October 7-9, 2013. The General Chairs were Prof. H. Fatih Ugurdag from Ozyegin University, Turkey, and Prof. Luis Miguel Silveira from Tech. Univ. of Lisbon, Portugal. The Program Chairs were Prof. Alex Orailoglu from UCSD, USA and Prof. Luigi Carro from UFRGS, Porto Alegre, Brazil. The book with best papers extended versions was again published by Springer (Fig. 17).

In 2014, the conference was organized in Playa del Carmen, Mexico, October 6-8, 2014. The General Chairs were Arturo Sarmiento Reyes from INAOE, Puebla, Mexico and Prof. Ricardo Reis from UFRGS, Porto Alegre, Brazil. The Program Chairs were Prof. Luc Claesen, from University of Hasselt, Belgium and María Teresa Sanz, from 


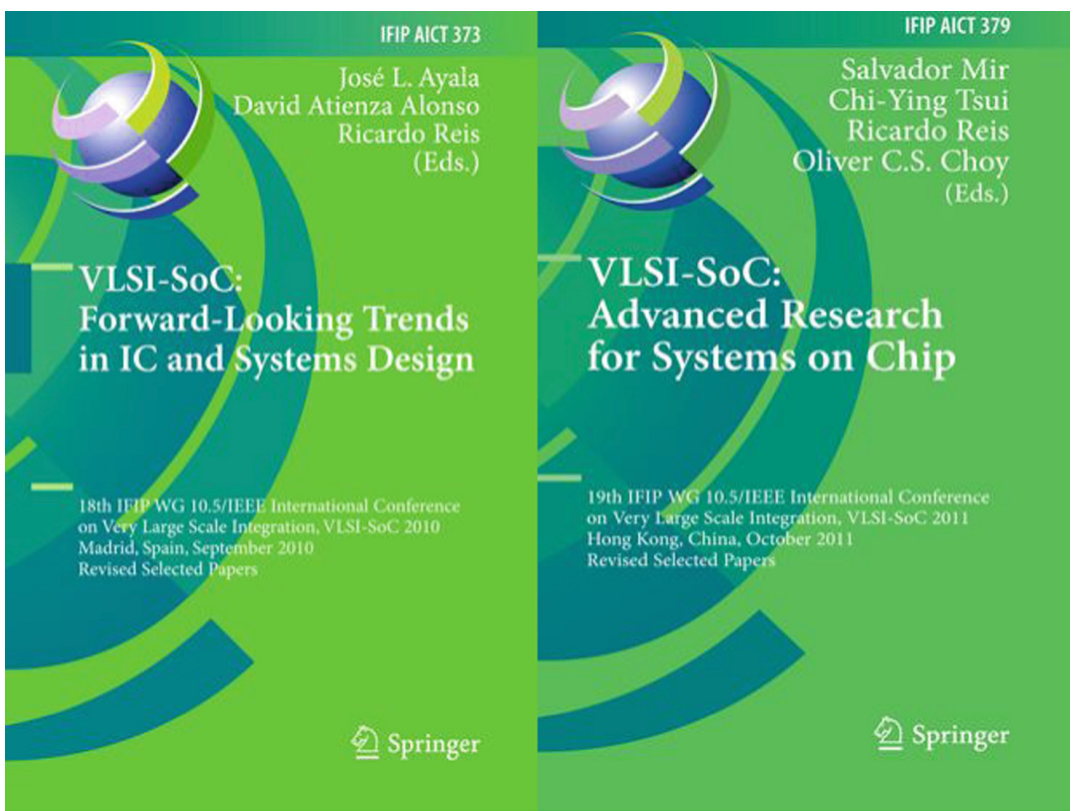

Fig. 16. Covers of the VLSI2010 and VLSI2011 books with extended versions of best papers published by Springer Publishers [18, 19].

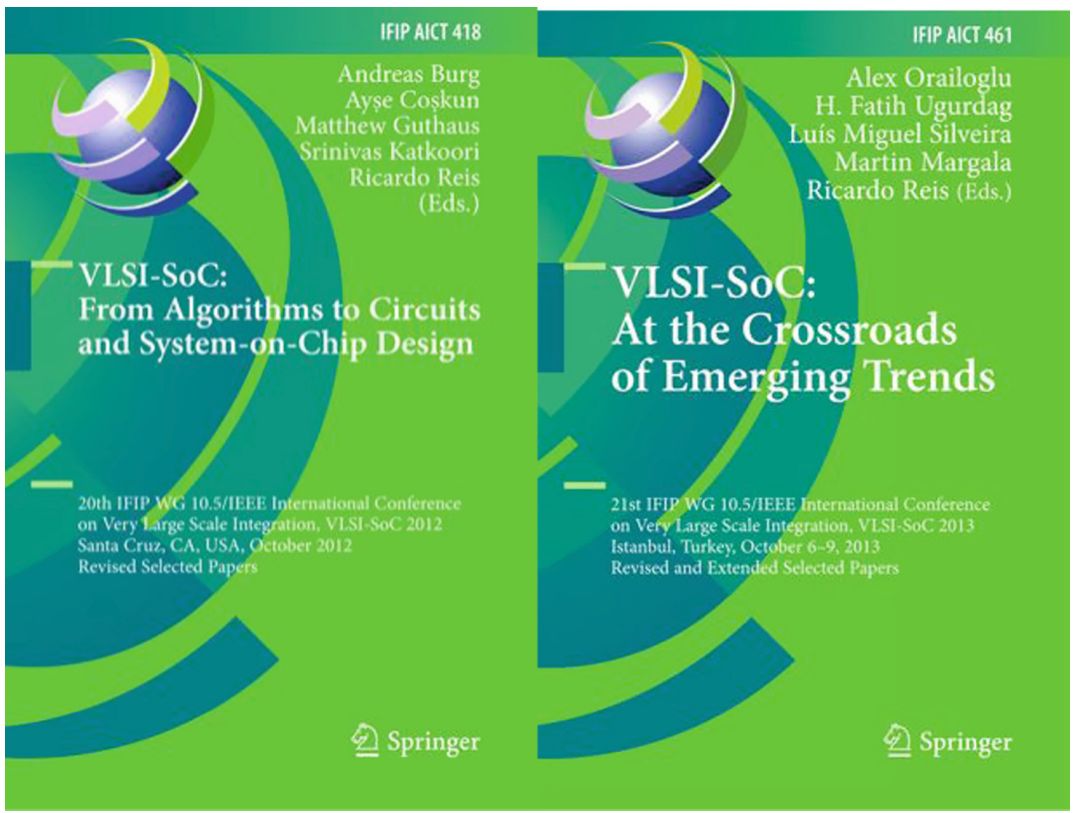

Fig. 17. Covers of the VLSI2012 and VLSI2013 books with extended versions of best papers published by Springer Publishers [20, 21]. 
INAOE, México. The book with best papers extended versions was again published by Springer (Fig. 18). In 2015, the event was organized in Daejeon, Korea, October 5-7, 2015. The General Chairs were Naehyuck Chang, from KAIST, Korea and Prof. Kiyoung Choi, from Seoul National Univ, Korea. The Program Chairs were Youngsoo Shin, from KAIST, Korea and Prof. Chi-Ying Tsui, from HKUST, Hong Kong. The book with best papers extended versions was again published by Springer (Fig. 18).

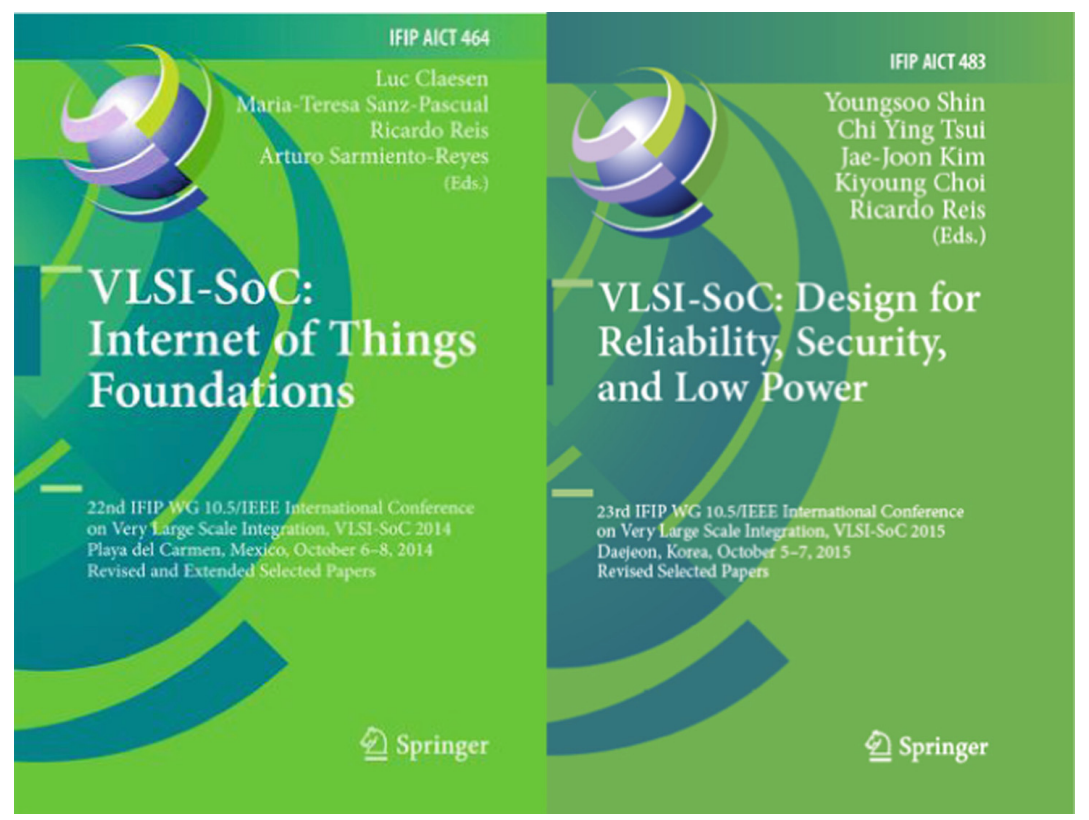

Fig. 18. Covers of the VLSI2014 and VLSI2015 books with extended versions of best papers published by Springer Publishers [22, 23].

In 2016, the conference was organized in Tallin, Estonia, September 7-10, 2015. The General Chairs were Prof. Jaan Raik, from Tallinn UT, Estonia and Prof. Ian O'Connor, from ECL Lyon, France. The Program Chairs were Prof. Thomas Hollstein, from Tallinn UT, Estonia, Germany and Prof. Michael Hübner, from Ruhr-Univ Bochum, Germany. The book with best papers extended versions was again published by Springer (Fig. 19). In 2017, the event was organized in Abu Dhabi, UAE, October 7-10, 2017. The General Chairs were Prof. brahim (Abe) M. Elfadel, from Masdar Institute of Science and Technology, UAE and Prof. Fatih Ugurdag, Ozeyegin University, Turkey. The Program Chairs were Prof. Mihalis Maniatakos, from New York University, Abu Dhabi, UAE and Prof. Matteo Sonza Reorda, from Politecnico di Torino, Italy.

In 2018, VLSI-SoC was organized in Verona, Italy, October 8-10, 2018. The General Chairs were Prof. Graziano Pravadelli from University of Verona, Italy and Prof. Todd Austin from the University of Michigan, USA. The Program Chairs were 


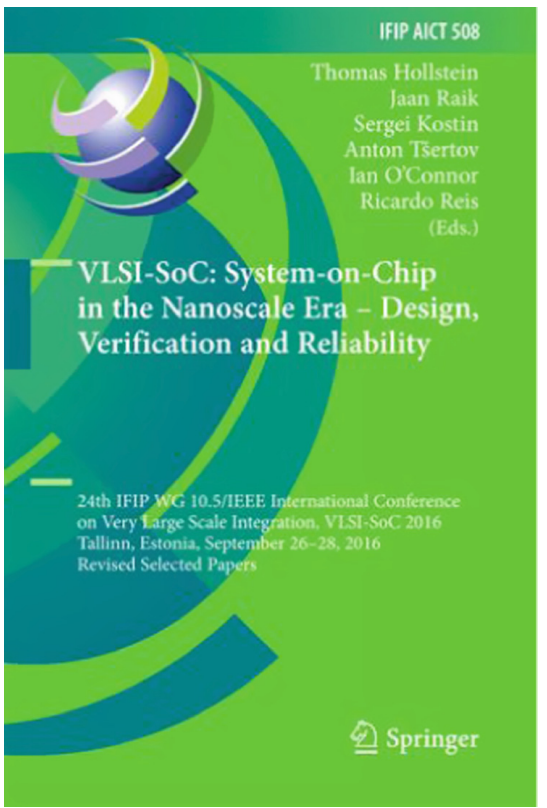

Fig. 19. Cover of the VLSI2016 book with extended versions of best papers published by Springer Publishers [24].

Prof. Nicola Bombieri from University of Verona, Italy and Prof. Masahiro Fujita from University of Tokyo, Japan.

In 2019, the conference is being organized in Cusco, Peru, October 6-9, 2019. The General Chairs are Prof. Carlos Silva-Cardenas, from PUCPeru, and Prof. Ricardo Reis, from UFRGS, Porto Alegre, Brazil. The Program Chairs are Prof. Giovanni De Micheli, from EPFL, Switzerland and Prof. Pierre Emmanuel Gaillardon, from Utah University, USA. In 2020, the conference will be organized in Salt Lake City, USA and in 2021 it will be in Singapore.

\section{Conclusions}

VLSI-SoC is a real global event in the field of Very Large Scale Integration Systems and Systems on a Chip. Each year it moves around the world, discussing and presenting the results of researches on state-of-art. The books published during these 38 years are a good witness of the evolution of the VLSI and SoC design technology in the world. 


\section{References}

1. Grey, J.: VLSI81: Very Large Scale Integration. Academic Press, London (1981). ISBN 9780122968600

2. Anceau, F., Aas, E.: VLSI83: VLSI Design of Digital Systems, North Holland, Amsterdam. ISBN 9780444867513

3. Hörbst, E.: VLSI85: VLSI Design of Digital Systems, North Holland, Amsterdam. ISBN 9780444879202

4. Séquin, C.: VLSI87: VLSI Design of Digital Systems, North Holland, Amsterdam. ISBN 9780444703705

5. Musgrave, G., Lauther, U.: VLSI89: VLSI Design of Digital Systems, North Holland, Amsterdam. ISBN 9780444883445

6. Halaas, A., Denyer, P.: VLSI91, North Holland, Amsterdam. ISBN 0-444-89019-X

7. Yanagawa, T., Yvey, P.: VLSI93, North Holland, Amsterdam. ISBN 0-444-89911-1

8. ASP-DAC 1995/CHDL 1995/VLSI 1995. IEEE Press. ISBN 4-930813-67-0

9. Reis, R., Claesen, L.: VLSI: Integrated Systems on Silicon. Chapman \& Hall, London (1997). ISBN 0-412-82370-5

10. Silveira, L., Devadas, S., Reis, R.: VLSI: Systems on a Chip. Kluwer Publishers, Boston (2000). ISBN 0-7923-7731-1

11. Robert, M., Rouzeyre, B., Piguet, C., Flottes, M.-L. (eds.): SOC Design Methodologies. IFIP, vol. 90. Kluwer Publishers, Boston (2001). https://doi.org/10.1007/978-0-387-355979_40. ISBN 978-1-4757-6530-4

12. Glesner, M., Reis, R., Indrusiak, L., Mooney, V., Eveking, H. (eds.): VLSI-SOC: From Systems to Chips. IFIP, vol. 200, p. 316. Springer, Boston (2006). https://doi.org/10.1007/ 0-387-33403-3. ISBN 0-387-33402-5

13. Reis, R., Osseiran, A., Pfleiderer, H.-J. (eds.): VLSI-SoC: From Systems to Silicon. IFIP, vol. 240. Springer, Boston (2007). https://doi.org/10.1007/978-0-387-73661-7. ISBN 978-0387-73660-0

14. De Micheli, G., Mir, S., Reis, R. (eds.): VLSI-SoC: Research Trends in VLSI and Systems on Chip. IFIP, vol. 249. Springer, Boston (2008). https://doi.org/10.1007/978-0-387-74909-9. ISBN 978-0-387-74908-2

15. Reis, R., Mooney, V., Hasler, P. (eds.): VLSI-SoC: Advanced Topics on Systems on a Chip. IFIP, vol. 291. Springer, Boston (2009). https://doi.org/10.1007/978-0-387-89558-1. ISBN 978-0-387-89557-4

16. Piguet, C., Reis, R., Soudris, D. (eds.): VLSI-SoC: Design Methodologies for SoC and SiP. IFIP AICT, vol. 313. Springer, Heidelberg (2010). https://doi.org/10.1007/978-3-64212267-5. ISSN 1868-4238

17. Becker, J., Johann, M., Reis, R. (eds.): VLSI-SoC: Technologies for Systems Integration. IFIP AICT, vol. 360. Springer, Heidelberg (2011). https://doi.org/10.1007/978-3-64223120-9. ISSN 1868-4238

18. Ayala, J.L., Atienza Alonso, D., Reis, R. (eds.): VLSI-SoC: Forward-Looking Trends in IC and Systems Design. IFIP AICT, vol. 373. Springer, Heidelberg (2012). https://doi.org/10. 1007/978-3-642-28566-0. ISBN 978-3-642-28565-3, ISSN 1868-4238

19. Mir, S., Tsui, C.-Y., Reis, R., Choy, O.C.S. (eds.): VLSI-SoC: Advanced Research for Systems on Chip. IFIP AICT, vol. 379. Springer, Heidelberg (2012). https://doi.org/10.1007/ 978-3-642-32770-4. ISSN 1868-4238, ISBN 978-3-642-32769-8

20. Burg, A., Coșkun, A., Guthaus, M., Katkoori, S., Reis, R. (eds.): VLSI-SoC: From Algorithms to Circuits and System-on-Chip Design. IFIP AICT, vol. 418. Springer, Heidelberg (2013). https://doi.org/10.1007/978-3-642-45073-0. ISBN 978-3-642-45072-3 
21. Orailoglu, A., Ugurdag, H.F., Silveira, L.M., Margala, M., Reis, R. (eds.): VLSI-SoC: At the Crossroads of Emerging Trends. IFIP AICT, vol. 461. Springer, Cham (2015). https://doi. org/10.1007/978-3-319-23799-2. ISBN 978-3-319-23798-5

22. Claesen, L., Sanz-Pascual, M.-T., Reis, R., Sarmiento-Reyes, A. (eds.): VLSI-SoC: Internet of Things Foundations. IFIP AICT, vol. 464. Springer, Cham (2015). https://doi.org/10. 1007/978-3-319-25279-7. ISBN 978-3-319-25278-0

23. Shin, Y., Tsui, C.Y., Kim, J.-J., Choi, K., Reis, R. (eds.): VLSI-SoC: Design for Reliability, Security, and Low Power. IFIP AICT, vol. 483. Springer, Cham (2016). https://doi.org/10. 1007/978-3-319-46097-0. ISBN 978-3-319-46096-3

24. Hollstein, T., Raik, J., Kostin, S., Tšertov, A., O’Connor, I., Reis, R. (eds.): VLSI-SoC: System-on-Chip in the Nanoscale Era - Design, Verification and Reliability. IFIP AICT, vol. 508. Springer, Cham (2017). https://doi.org/10.1007/978-3-319-67104-8. ISBN 978-3-31967103-1

Open Access This chapter is licensed under the terms of the Creative Commons Attribution 4.0 International License (http://creativecommons.org/licenses/by/4.0/), which permits use, sharing, adaptation, distribution and reproduction in any medium or format, as long as you give appropriate credit to the original author(s) and the source, provide a link to the Creative Commons license and indicate if changes were made.

The images or other third party material in this chapter are included in the chapter's Creative Commons license, unless indicated otherwise in a credit line to the material. If material is not included in the chapter's Creative Commons license and your intended use is not permitted by statutory regulation or exceeds the permitted use, you will need to obtain permission directly from the copyright holder.

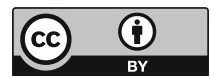

